\title{
The Governance of Public-Private Ties Model: How to Govern the PPPs Infrastructure Project Effectively (An Indonesia Case)
}

\author{
Krist Ade Sudiyono $^{1 *}$, Tirta Mursitama ${ }^{1}$, Boto Simatupang ${ }^{1}$, Mohammad Hamsal ${ }^{1}$ \\ ${ }^{1}$ Doctor Research in Management Program, Bina Nusantara University \\ Email: adesudiyono@yahoo.co.id
}

\begin{abstract}
Even though the Public-Private Partnerships model in public infrastructure provision has proliferated in the last decade, its effectiveness with respect to the addressed problems has remained very challenging. The purpose of this study is to explore how the public-private ties model strategically managed in creating value to involved parties as well as to other stakeholders. This empirical study consolidated the value creation theories in strategic management and theories of governance in new public management discourse. It utilized an original primary dataset collected by a survey of 132 involved companies in Indonesia infrastructure development. There are at least two significant findings. First, the public infrastructure provision is beyond physical development activities. It is an economic and public value creation process. Second, the dynamic capability exploration must be executed in a way of democratic accountability, having strong stakeholders' procedural legitimacy, and public participation enforcement. The value creation needs a collaborative governance in accordance that the model is vulnerable due to endemic conflict and tensions. This research leaves out two side effect of governance. Other than as a value creation component, the governance also can perform as a value destruction of the public-private ties model. These findings have important theoretical and managerial implication for public policy to encourage private willingness participating in infrastructure development.
\end{abstract}

Type of paper: Empirical research

Keywords: Collaborative governance; Cross-sector collaboration; Public-private partnerships; Public-private ties; Value Creation

\section{Introduction}

The most strategic criticisms to the public-private ties of Public-Private Partnerships (PPPs) project is whether the model can create public value and give maximum benefits to public (Agranoff, 2007, 2012; Page et al., 2015). Therefore, the value creation process of publicprivate ties, which occurred in public sphere, needs a specific governance (Page et al., 2015). As part of the new public management discourse (Grueining, 2001; Mongkol, 2011), this model explores collective authorities and capabilities (Seitanidi and Lindgreen, 2010; Sharma, 2007). The collective inter-organizational advantages, such as: distinctive resources, core competencies, knowledge, expertise, business model, etc., should be explored and exploited to create enhanced public and network values (Allee, 2008a, 2008b). 
Featuring this critical interdependencies between public versus private interest and inherent tensions between private rent-driven objectives and wider public value outcome (Mahoney et al., 2009), these public-private ties requires a critical examination of the value creation effectiveness. According to Reynaers and De Graaf (2014), it should be analyzed on public value perspective, referring to: strategic model objectives - availability and reliability of public goods and services; structured process to enforce transparency and accountability norms; as well as moral and ethics guidance during project implementation. Recent research suggests that the novel form of public-private ties warrant a systematic theoretical inquiry from organizational capabilities, governance, and resulting value perspectives.

In the case of Indonesia, unfortunately, infrastructure that acts as the catalyst of growth has been lagging. Indonesia needs USD 400 billion to develop and revitalize its public infrastructure, such as toll roads, seaports, airports, power plants, water treatment plants and distribution during medium development plan of 2015-2019. A part of 36\% of this budget requirement is expected to be contributed by private participation. Even though infrastructure is a lucrative sector, but due to its unique characteristic with usually capital intensive, long-term investment, inelastic demand, monopolistic market and affect to social condition, to boost private participation is not easy. Encouraging private participation needs not just offering many benefits (long-term stable income, resilience to economic downturn, portfolio diversification benefits and attractive returns), but also a suitable structure and business model, solid and accurate regulation, feasible distribution of risks, and other business context consistency.

This study addresses mentioned challenges. To enhance its effectiveness, the value creation of public-private ties needs a collaborative governance. The authors utilize a value creation and theory of governance from strategic management and new public management discourses. In the next section, drawing primary in theoretical and framework of the crosssector collaboration model, we delineate general antecedent of value creation process and governance, considering collaboration contexts as strategic contingencies, and subsequently describing a suitable governance typology of public-private ties model. The study concludes with an extensive discussion in both theoretical as well as managerial contextual implication.

\section{Literature Review}

Building on prior work in the cross-sector collaboration (CSC) model, the assessment of value creation process should be re-articulated in terms of network efficiency, effectiveness, and equity (Dubnick and Frederikson, 2011). The model must enhance value network and solve public challenges: creating value for involved partners, shared benefits and risks, utilize associational / transferred values and interactional / synergic value (Austin and Seitanidi, 2012a, 2012b). The CSC model should significantly contribute to operational efficiency as well as strategic effectiveness (Tulder et al., 2016). Efficiency of the model can be seen as an internal value added of collaboration, measured by both project's output and outcome comparing to utilized resources and capabilities (cost-benefit analysis). While, the strategic effectiveness of collaboration, measured in both mission and issue- related performance, impact assessment to both original mission objectives mandated and addressed social problem background. We argue that the nature of the issue as well as the degree of efficiency and effectiveness are influenced by the context in which the partnership is initiated. 
Drawing on externalities and transaction cost economics theory, there are several rationales of PPPs infrastructure projects. The PPPs model create value when it enables the realization of economic opportunity. This private rent-driven objective must imply positive externalities to public value objectives to address pending social concerns and commons dilemma of public goods and services availability (Brinkerhoff \& Brinkerhoff, 2011; Mahoney et al., 2009; Rangan et al., 2006). Second rationale is resources complementary or recombination. The PPPs should extend the access and advantage private sector resources, managerial and entrepreneurial skills, know-how for public-resources creation and allocation decisions (Klein et al., 2010; Rangan et $a l .$, 2006). Moreover, the rationale is a cost minimizing or efficiency enhancement, including the bundling of investment and operations to reduce life-cycle costs, delivery quality and social benefit enhancing, and cost-reduction innovations; enhancing public sector efficiency through introduction of competition and higher-powered incentives; and reduction of fiscal pressures and public debt (Brinkerhoff \& Brinkerhoff, 2011).

Furthermore, reviewing major theoretical framework form empirical and non-empirical studies finding during 2006-2015, Bryson, Crosby, and Stone (2015) mentioned that determinants of the collaborative governance of CSC model are rooted in the external context, including resources conditions, policy and legal frameworks, and politics and power condition. Even when general antecedent favors the formation of CSC model (such as: limitation of resources, institutional mandates, and the need to address public issue due to sector failure), they are unlikely to get under way without the presence of specific drivers or initial condition, political agreement on initial aims, recognized interdependence and pre-existing relationship. The strategic formulation of this model, in the form of collaborative processes and collaboration structures design, relies to a great deal on lateral relations, informal networks, and more power sharing. While the implementation process typically produces a reemergence of reliance on hierarchy, formal networks, and less power sharing. For collaboration to thrive, the publicprivate ties need ongoing sponsorship from people who have formal authority and championing from people who use mainly informal authority to engage partners in their mutual works. This leadership component is strategically required to enforce a collaborative governance in accordance that the model is vulnerable due to endemic conflict and tensions. Both are likely to be present in this multi-organizational arrangement due to either power imbalance, competing institutional logics, autonomy versus interdependence, stability versus flexibility, inclusivity versus efficiency, and internal versus external legitimacy.

The value creation effectiveness of public-private ties may have best outcomes and accountabilities, also needs to be equipped with collaborative capacity and competencies. Key individual in public-private ties must be equipped with specialized power, specialized expertice, and attitudes deemed helpful for collaborative environment. It need interpersonal understanding, openness to collaboration, and concern for the common good. The individual ability to work across boundaries, analyze and involve stakeholders, engage in strategic planning, and participate in teamwork are believed as some mandatory public-private ties competencies to employ certain collaboration strategies and enjoy higher mutual trust and greater goal alignment on public value creation.

\section{Research Methodology}

This research utilized a verificative-explanatory research method, a combination of literature study to identify major variables and dimensions of public-private ties value creation process, 
and quantitative analysis to verify correlation among variables in the CSC model (Cresswell, 2012). Research model is a multi-dimensional, developed in second-order construct model. Construction of latent variable (second order) composed from some of dimension constructs (first order). The conceptual framework developed from results of literature study, tested empirically through hypothesis testing on the relationships between variables. We utilize second generation of multivariate analysis, the analysis of structural equation models (SEM) with partial least square approach (PLS). This approach is an emerging methodological widely used in quantitative research for a model that involves latent variables with some indicators. PLS make no parametric assumptions and focus on the significance of relationship between dependent and independent variables, instead of analyzing the overall model fit, as in covariancebased structural equation modeling.

The authors explore the collaborative dynamic capability, a core antecedent of CSC model value creation (Teece, Pisano, and Shuen, 1997; Allred et al., 2011), as the first hypothesis (H-1). Following literature study, there are several reflective dimensions of collaborative dynamic capability identified, such as: effective leadership, collaborative fluency, inter/ entrepreneurial and absorptive capacity to reconcile the interested parties' objectives with common collaboration objectives. In collaboration, it will involve several activities of governing process, administrative, attitude on autonomous, joint initiatives, and norms of reciprocity and mutual trust. The model needs an effective leadership to demonstrate a collaboration fluency; entrepreneurial in managing collective resources; as well as a collaborative capacity to respect for autonomous, togetherness (collective and collegial) and mutually trusting (Agranoff, 2007, 2012; Ansel and Gash, 2008; Bryson, Crosby, and Stone, 2006; Emerson, Nabatchi, and Balogh, 2011; Thomson and Perry, 2006; Koschmann, Kuhn, and Pfarrer, 2012).

Furthermore, the authors are examining the collaborative governance instead of as a mediating variable $(\mathrm{H}-2)$ as well as moderating variable $(\mathrm{H}-3)$ of collaborative dynamic capability exploration to the effective value creation relationship. Adopting the governance terms of Assens and Lemeur (2016), there are five components must exist in collaboration model. First, legitimacy that gives any actor a voice in decision making to reach consensus despite divergent interests. Second, orientation that benefits all and not just some. Third, efficiency resulting from the rational use of resources to produce the best possible result. Fourth, accountability of associated members for the transparency of information. Finally, the equity that comes with the principles of equality and impartiality. The public-private ties should qualify the vertical and horizontal democratic accountability. Its implementation must follow procedures with having strong legitimacy by stakeholders. And, it may provide a normative consensus about rights, benefits and prerogative of the society, in addition to create a space for individuals to fulfill their responsibility towards their community and country through active participation in sustainable development model (Page et al., 2013).

The authors extend private actors involved in Indonesia infrastructure development projects as unit analysis of this study. A 40-question survey was developed to collect data on wide variety of subject matters. It describes a structured questionnaire using 4 points Likert scale from "strongly agree" to "strongly disagree". To ensure the validity of questionnaire, the authors made several changes following review comments from two-scholar experts in the research fields and piloting test feedback with three targeted respondents. The authors employed the four eyes survey application (www.getfoureyes.com), which providing respondent access easily to the research questionnaire homepage. The study received 186 valid responses from 132 companies, 


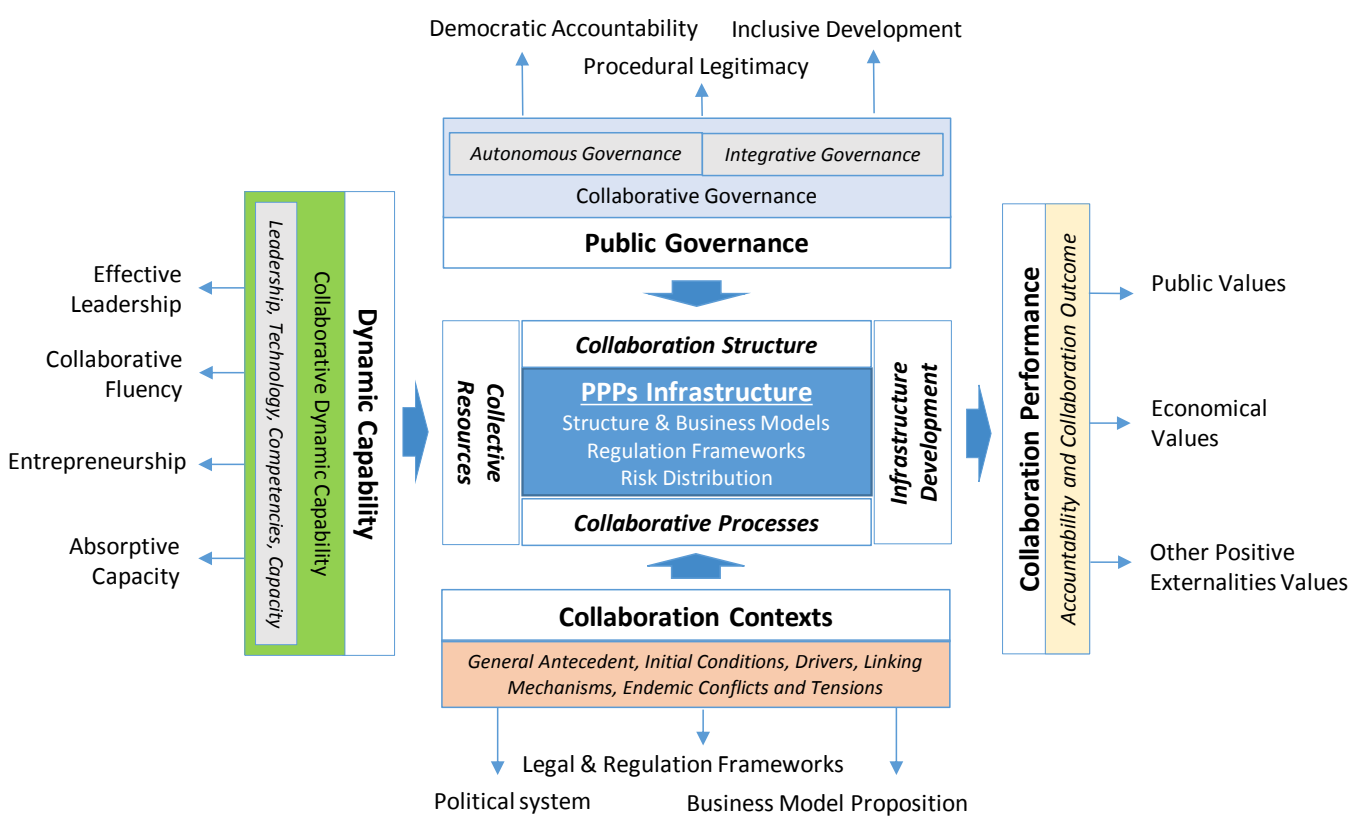

Figure 1. The Integrated Value Creation Model of PPP Infrastructure Project

coming from two segments respondent: infrastructure holding company (52 companies), and the project business entity company ( 80 companies) of toll road sector, private power plants, ports (seaport and airport), telecommunications and information technology, and clean water treatment and distribution in Indonesia. Of the total sample, almost $70 \%$ of questionnaire were responded to by the top management team with more than 10 years' experiences in the industry (28\%) and for 3-10 years' experiences (60\%) respectively. It gives more confidence that the research addressed to the right respondents and validity of research result.

\section{4. $\quad$ Results}

It is confirmed that the value creation process in the form of a suitable structure and business model, a solid and accurate regulatory framework, balanced distribution of risk, requires a mandatory constructive governance of this CSC model. This empirical study accepted the first hypothesis (H-1). To enhance network efficiency, effectiveness, and synergy of collaboration, we need a collaborative dynamic capability. It is a strategic management capability to integrate, develop, and reconfigure the collective resources and capabilities. It needs an effective leadership, collaborative fluency, intra/entrepreneurship in managing collective resources, and absorptive capacity (Teece, Pisano, and Shuen, 1997).

As fully aware, the collaboration model involving public organization needs to produce collective benefits and meets its objectives and mandates. The CSC model qualifies both vertical and horizontal democratic accountability; follows the procedure with strong stakeholder legitimacy; as well as providing normative consensus that guarantee the rights, benefits, and prerogative of the communities. In addition to creating a space for individuals to fulfill its obligations towards the community and the country, it should empower public an active participation in sustainable infrastructure development. In this view, the collaborative governance is necessary to manage the collaboration context. A poorly managed of collaboration context (conditions of political power, legal and policy framework; resource dependencies; endemic conflicts and tension) can rise a destruction of value creation process. 
This study shows a two sides effect of governance. In addition to being a value creation factor, application of wrong governance will be a factor in value destruction. A governance provides positive mediation of value creation process if being used as a strategic tool, embedded at each process and structure of public-private ties. Conversely, if the governance to be the ultimate objective, as outsider's moderation tools to supervise and moderate the relationship of the government and private parties, in some cases, give a negative impact to the value creation process, becoming a destructive factor to the project. This empirical study accepted the second hypothesis (H-2), while rejected the third hypothesis $(\mathrm{H}-3)$.

This study also discovers two main governance typologies spectrum of the CSC model: autonomous and integrative typology. This typology is influenced by the pull of externalities value occurred, the contribution of idiosyncratic capabilities and resources among parties, as well as the relative value between productivity and efficiency of the governance process. The autonomous model lays down the value creation process based on productivity and cost allocation. On the other side, the integrative model puts the value creation process on the framework of complementary resources and capabilities, as well as the relativity of costefficiency value of governance (Kivleniece and Quelin, 2012).

In the context of Indonesia PPPs infrastructure project, this study shows a preference of private in the autonomous governance model typology. Although perceived as not significantly influencing the value creation process, the collaboration context are tinged with uncertainty and inconsistency, weak government resources and capabilities contribution, and a belief in the superiority of private capabilities in innovation process and more governance efficiency. The private tends to minimize the influence of this collaborative context, by selecting projects that apply the autonomous governance typology model.

\section{Discussion}

According to Emerson, Nabatchi, and Balogh(2012), themain determinants of the CSCmodelare rooted from external context. As a complex dynamic system, the collaboration context interacts and engages in a wide environment. They are widely spreading up into general antecedent; initial condition, collaboration drivers, and relationship mechanism; process and structure of collaboration and relationship of them; endemic conflict and tension; as well as the expected outcomes and accountability of the collaboration model initiatives (Bryson, Crosby, and Stone, 2015). Endemic conflict and tension occurred due to the difference in goals and expectations, autonomous and interdependence against collective goals and interests (Thomson and Perry, 2006). A difference view of stability-flexibility, inclusivity-efficiency, unity-diversification, and internal-external legitimacy due to difference of views in strategies and tactics being used, as well as controlling power of processes and outcomes of parent organization will affect an occurred tension (Provan and Kenis, 2008).

The components of this institutional environment should be managed properly. It is a strategic contingency that will influence, but not always determine, the successful of managerial and collaboration activities. In this perspective, collaborative process and structure of public-private ties model requires an agreed common antecedent. It should get a politically approval over the initial goals, recognition of constructive interdependence, and the initial relation between the parties, as its background. In addition to fulfilling public accountability, the project has to enhance a public value. It must contribute to public goods or services provision; the complementary of 
private resources for public resource creation; as well as adding differentiation of cost efficiency. Positive externality in the economic aspects (an attractive investment return), should also give a positive externality to achieve objectives of those three strategic rationalities of public values.

As already mentioned earlier, the value creation of the PPPs infrastructure project tinged with interest polarization, influenced by motive behind the rational objectives of this project. The government draws it towards political benefit, and private is oriented toward the benefits of economic value wants to achieve. On the other hand, the project has also drawn the interest of community, as a political constituent, who want greatest social benefits from the existence of this infrastructure project. The complexity, dynamics, and extent of this collaborative context able to frustrate the parties involved, and become the cause of collaborative inertia (Huxham and Vagen, 2005). The perpetrators of the collaboration model demonstrate a resistance attitude towards working in CSC model. The collaborative inertia is a destructive factor that sometimes and can be a factor inhibiting the value creation process and effectiveness of this model.

A PPPs infrastructure project will attract a private involvement if the perceived benefits it offered has a significant value differences with the incurred resources and the governance costs. In this perspective, the collaboration context of the PPPS infrastructure project, integrated with the perception over value proposition contributed by each party, becomes the business risks that affect private involvement. The value creation effectiveness is tightly influenced by the occurred positive externalities value, effective contribution of idiosyncrasies resources and capabilities by the parties, and relativity of productivity and efficiency of its governance (Kivleniece and Quelin, 2012; Ragan, et al., 2006). It is in line with the economy governance theory (Ostrom, 2010; Williamson, 2009, 2010), and the knowledge accessing theory of strategic alliances (Grant and Baden-Fuller, 2004).

In the end, the collaboration context conditions will affect private preferences on governance typology and business model of the PPPs infrastructure project (Emerson, Nabatchi, and Balogh, 2012; Kivleniece and Quelin, 2012). The choice of CSC model governance typology, which are autonomous and integrative governance (Kivleniece and Quelin, 2012), is influenced by the private perspective form to reduce environmental uncertainty. If it is highly political, legal, and regulatory uncertainties, then the autonomous governance typology tends to be preferred. The same thing happens from the perspective of accessing and exploiting resources. If the value creation effectiveness is highly dependent on exploiting public property-based resources and private knowledge-based resources, then the autonomous governance typology is also favored. Conversely, for the highly uncertainty in market condition and technological environment conditions; the strong attraction towards the positive externalities of the public value, the high utilization of public knowledge-based resources, as well as the perspective of beliefs on private capacity to access strong political resources, then the private tends to choose integrative governance as their preference.

The PPPs infrastructure concession business model: build, operate, and transfer (BOT) model; built, own, operate, and transfer (BOOT) model; are some public-private collaboration model that tend to apply the autonomous governance model. While the sub-concession business models (e.g. design and build model; joint operations; profit-sharing models, joint-venture model, etc.) are the examples of integrative governance model. Including in the integrative governance model are the forms of hybrid public-private ties model, which requires a government support in the form of business viability supports. 
This study has several limitations that might become the avenue for future research. First, this study was conducted on private party perspective. All questions were designed to collect private perceived perspective on several subject matters. Consequently, the analysis and interpretation of the findings reflect the private perspective. It is recommended to get the same views coming from public perspective. Further study with structured dyadic method involving public and private perspective simultaneously to addressed matters is required. Second, the data of this study were based on the feedback from private who has involved inside the model of PPPs infrastructure project. Future study, specifically on private parties who has not participated in this model, can give more benefits to encourage the broader private participation in infrastructure development using this model.

\section{Conclusion}

The public-private ties in infrastructure development (PPPs infrastructure project) is a dynamic and complex. It is the CSC model requires a comprehensive multi-dimensional analysis and solution. The PPPs infrastructure project is a strategic business alliance model. Public infrastructure provision is beyond physical development activities. It is an economic and public value creation process. This model requires appropriate business structure and engagement in accordance with the parties' value proposition; a solid and accurate regulatory framework; as well as a balanced and viable risk distribution.

The value creation effectiveness should be strategically managed consolidating strategic management discourse in public management areas. It needs an integrative value creation framework, exploring collaborative dynamic capability and collaborative governance architectures, to manage collaboration context to achieve project objectives and expected outcomes. Based on this integrative framework, the PPPs infrastructure project can be redefined to be: "the public and economic value creation process in public infrastructure provision, by exploring the public-private ties' collaborative dynamic capability, used to design and implement constructive collaborative governance, in managing and addressing various issues of accompanying inherent collaboration context."

In the context of Indonesia, ineffectiveness of PPPs infrastructure project, from private perspective, is due to value destruction of this CSC model. Although the influence tends to be weak and insignificant, the value destruction due to unfavorable collaboration context leads to collaborative inertia phenomenon. It is mainly due to the lack of clarity of authoritative text on general antecedents, the inconsistencies in legal regulatory framework and the business partnership engagement being carried out, as well as the endemic conflict and tension of project implementation. We propose an institutional restructuring to handle governance mechanism of Indonesia PPPs infrastructure projects. The existence of a strong project sponsor from the highest political authority should be followed by the presence of a strong integrated project champion institution. The existence of this institution will act as a contracting agency and project management office of the PPPs infrastructure project. Besides to be a single access of potential private investors, this institution will lead a public communication addressing a collaboration context especially in public value creation of public-private ties model in public infrastructure provision.

Private preference to the autonomous governance typology, proves that private perceptions of value contribution and collaborative capabilities of government officers in the PPP infrastructure 
project are still weak. It needs a capability and capacity enhancement. Optimizing resources to address the financing gaps for the infrastructure project in Indonesia, should be based on this facts and conditions. The infrastructure projects with financially feasible should be directed towards private participation role. Other infrastructure projects with low and inadequate project feasibility, or project in the economically viable stages, should be taken over by the government or through its development agents (state-owned enterprises - BUMN, regionalowned enterprises - BUMD).

\section{References}

Agranoff, R., (2007). Managing within networks: Adding value to public organizations. Georgetown University Press.

Agranoff, R., (2012). Local governments and their intergovernmental networks in federalizing Spain. McGill-Queen's Press-MQUP.

Allred, C.R, Fawcett, S.E, Fallin C, and Magnan, G.M., (2011). Adynamic collaboration capability as a source of competitive advantage. Decision Sciences Journal, 42(1), 129-160.

Allee, V., (2008a). Value network analysis and value conversion of tangible and intangible assets. Journal of Intellectual Capital, 9(1), 5-24.

Allee, V.,(2008b). Value-creating networks: Organizational issues and challenges. The Learning Organization, 16 (6), 427-442.

Ansell, Chris., and Gash, Alison (2007). Collaborative governance in theory and practice. Journal of Public Administration Research, 18(4), 543-571.

Assens, C., \& Lemeur, A. C., (2016). Network Governance: The Theory. In Networks Governance, Partnership Management and Coalitions Federation (pp. 5-10). Palgrave Macmillan UK.

Austin, J. E., \& Seitanidi, M. M., (2012). Collaborative value creation: A review of partnering between nonprofits and businesses: Value creation spectrum and collaboration stages. Nonprofit and Voluntary Sector Quarterly, 41(5), 726-758.

Austin, J. E., \& Seitanidi, M. M., (2012). Collaborative value creation: A review of partnering between nonprofits and businesses. Partnership processes and outcomes. Nonprofit and Voluntary Sector Quarterly, 41(6), 929-968.

Bringkerhoff, D.W., and Bringkerhoff, J.M., (2011). Public-Private Partnerships: Perpective of purposes, publicness, and good governance. Public Administration and Development, $31(1), 2-14$.

Bryson, J. M., Crosby, B. C., \& Stone, M. M., (2006). The design and implementation of crosssector collaborations: Proposition from the literature. Public Administration Review, 66(12), 44-55. 
Bryson, J. M., Crosby, B. C., \& Stone, M. M., (2015). Designing and implementing cross-sector collaborations: Needed and challenging. Public Administration Review, 75(5), 647-663.

Creswell, J., (2012). Education Research: Planning, Conducting, and Evaluating Quantitative and Qualitative Research. 4'th edn. Pearson Education, Inc, MA

Dubnick, M., \& Frederickson, H. G., (2011). Public accountability: Performance measurement, the extended state, and the search for trust. Washington: National Academy of Public Administration and The Kettering Foundation.

Emerson, K., Nabatchi, T., and Balogh, S., (2012). An integrative framework for collaborative governance. The Journal of Public Administration Research and Theory, 22(1), 1-29.

Grant, R.M., and Baden Fuller, C., (2004). A knowledge accessing theory of strategic alliances. Journal of Management Studies, 41(1), 61-84.

Grueining, G., (2001). Origin and theoretical basis of New Public Management. International Public Management Journal, 4, 1-25.

Huxham, C., \& Vangen, S., (2013). Managing to collaborate: The theory and practice of collaborative advantage. Routledge

Klein, P. G., Mahoney, J. T., McGahan, A. M., \& Pitelis, C. N. (2010). Toward a theory of public entrepreneurship. European management review, 7(1), 1-15.

Koschmann, M.A., Kuhn T.R., \& Pfarrer M.D., (2012). A communication framework of value in cross-sector partnership. Academy of Management Review, 37(3), 332-354.

Kivleniece, I., \& Quelin, B. V., (2012). Creating and capturing value in public-private ties: A private actor's perspective. Academy of Management Review, 37(2), 272-299.

Mahoney, J. T., McGahan, A. M., \& Pitelis, C. N. (2009). Perspective - the interdependence of private and public interests. Organization Science, 20(6), 1034-1052.

Mongkol, K. (2011). The critical review of new public management models and its criticism. Research Journal of Business Management, 5(1), 35-43.

Ostrom, E. (2010). Beyond markets and states: polycentric governance of complex economic systems. Transnational Corporations Review, 2(2), 1-12.

Page, S. B., Stone, M. M., Bryson, J.M., and Crosby, B. C., (2013). Theorizing and Measuring the Public Value Created by Cross-Sector Collaboration. White paper presented at the Pubic Management Research Conference, Madison.

Page, S. B., Stone, M. M., Bryson, J. M., \& Crosby, B. C., (2015). Public value creation by cross-sector collaborations: A framework and challenges of assessment. Public Administration, 93(3), 715-732. 
Provan, K. G., \& Kenis, P., (2008). Modes of network governance: Structure, management, and effectiveness. Journal of public administration research and theory, 18(2), 229-252.

Rangan, S., Samii, R., \& Van Wassenhove, L. N., (2006). Constructive partnerships: When alliances between private firms and public actors can enable creative strategies. Academy of Management Review, 31(3), 738-751.

Reynaers, A. M. (2014). Public values in public-private partnerships. Public Administration Review, 74(1), 41-50.

Seitanidi, M.M., and Lindgreen, A. (2010). Editorial: Cross-sector social interactions. Journal of Business Ethics, 94, 1-7.

Sharma, C. K. (2007). New public management challenges and constrains. University of Botswana, Botswana.

Teece, D. J., Pisano, G, and Shuen, A., (1997). Dynamic capabilities and strategic management. Strategic Management Journal, 18(7), 509-533.

Thomson, A.M. and Perry, J.L., (2006). Collaboration process: Inside the black box. Public Administration Review, special issue, 20-32.

Tulder, R., Seitanidi, M. M., Crane, A., \& Brammer, S., (2016). Enhancing the impact of crosssector partnerships. Journal of Business Ethics, 135(1), 1-17.

Williamson, O. E., (1999). Strategy research: governance and competence perspectives. Strategic management journal, 1087-1108.

Williamson, O. E., (2010). Transaction cost economics: The natural progression. Journal of Retailing, 86(3), 215-226 